\section{Contributors}

Nigel De-Kare Silve

nigel.dekaresilver@londondeanery.ac.uk

Denis Pereira Gray is past President of the Royal College of General Practitioners and most other British medical institutions. He is famously an ex Editor of this Journal.

denis.pereiragray@btinternet.com

Chris Johnstone is a GP in Paisley. Like a grumpy Roman senator he ends every email communication with the puzzling postscript: The Quality and Outcomes Framework Must Be Destroyed. This may explain, possibly, why he no longer edits Hoolet, the late lamented journal of RCGP Scotland.

christopher.johnstone@ntlworld.com

Paul Hodgkin has more clever ideas in a week than most of us have in a lifetime. And he acts upon many of them. He founded Patient Opinion:

http://www.patientopinion.org.uk/ paul.hodgkin@patientopinion.org.uk

Alec Logan is the BJGP's Deputy Editor. aleclogan@dial.pipex.com

\section{Mike Fitzpatrick}

fitz@easynet.co.uk

Dan Edgcumbe is a GP registrar in Histon, Cambs. He would like to acknowledge John Salinsky for his helpfu contributions during the research process for these essays.

dr.edgcumbe@gmail.com

John Brooks is a GP in Congleton, Cheshire.

jbsbrooks@hotmail.co.uk

Lesley Morrison is a GP in the Scottish Borders.

Lesley.Morrison@borders.scot.nhs.uk

Emyr Gravell emyrwyn@doctors.org.uk

\title{
Wild things
}

'I come into the peace of wild things ...

... I rest in the grace of the world, and am free."

It was a scene of squalor that most of us have come across now and again on a home visit. He was an old farmer in an isolated farmhouse who had got more and more withdrawn as paranoia had set in and the result of self-neglect was difficult for even a battle hardened GP to stomach.

He'd already had a recent admission but had obviously struggled to cope even more since being home again. The pitiful state of his house was in stark contrast to the rosy picture painted by a 12-page risk assessment done on his discharge. It was a kind of Dorian Gray in reverse. The care plan had been meticulously completed. There were more boxes filled in than on a bumper Sudoku puzzle yet the neat order of the assessment hid a depressingly different, grim reality.

It's always sad to have to admit someone against their will but there was no option. The desolate estuary on which the farm was set was a lonely backdrop to the sad proceedings. We could have been hundreds of miles from civilisation yet this estuary which was now bleak and empty was once a thriving waterway. Big masted coal ships plied their trade along it, and if you looked closely you could still make out exaggerated curves on it's overgrown banks which had once been bustling jetties for these ships. We tend to think of civilisation as a one way process but it doesn't take long for the feral wilderness to take over again.

Now and again you have to accept that, despite all the progress, things are not tame. Illness is often difficult to keep neat and manageable and attempts to contain it with various tools such as risk assessments, no matter how detailed or well intentioned, can be misleading. I find it paradoxical that more measurement, and detailed analysis of outcomes doesn't always lead to greater satisfaction. Sometimes it seems to be the opposite, in fact, I have the impression that public and media criticism of GPs has been increasing since the Quality and Outcomes Framework was introduced.
The author Samuel Butler (1835-1902) said that 'A definition is enclosing the wilderness of an idea within a wall of words'. The more we try and enclose the wilderness of medicine in a wall of guidelines, protocols, and risk assessment the more dissatisfaction we generate when we aren't successful.

Whenever we are castigated in the media for something like not spotting dementia early enough or still not spotting meningitis or missing cancers, a top GP turns up in sackcloth and ashes, beating their academic breast and promising more protocols and training will be put in place to bring the rest of us up to speed to make sure that this distant corner of the wilderness is quickly tidied up. Yet it doesn't seem long until the next story is GPs undertreating depression or overtreating depression or knowing nothing about some rarity like Fanconi's syndrome. Sometimes I think it would be more honest if the spokesperson just held their hands up and said 'Yup it's a wild, wild world out there, most of us are doing our best but life, liberty and the pursuit of healthiness is still at times an unmanageable beast and as Friedman and Marsa, in the song Lucky Stars, eloquently put it: '... we're not as smart as we like to think we are'.

It might be liberating for everybody.

\section{REFERENCE}

1. Berry W. Sex, economy, freedom and community: eight essays. SOS Free Stock, 1994.

DOI: 10.3399/bjgp10X532549 